\title{
Clinical profile of patients with lupus nephritis
}

\author{
T.L. Skare, A.C. Schönrock \\ Rheumatology Unit, Hospital Universitário Evangélico de Curitiba, PR - Brazil
}

To the Editor

Lupus nephritis is the strongest predictor of systemic lupus erythematosus (SLE) patient's morbidity and mortality with a prevalence varying from 31 to $65 \%$ according to the studied population (1). As the onset of lupus nephritis is usually silent, knowing possible association with others symptoms is useful in order to keep of better vigilance on patients with higher possibility to develop it.

Pistiner et al described that lupus patients with nephritis also have an increased frequency of other severe lupus manifestations (2). According to Huong et al, in a study of 180 patients with lupus renal involvement, patients with nephritis suffered more commonly from malar rash, psychosis, myocarditis, pericarditis, lymphadenopathy and hypertension. Seizures, thrombocytopenia and secondary fibromyalgia were less frequent in these patients (3). Some investigators have proposed that rheumatoid like arthritis are associated with lower incidence of renal disease (4); in an opposite way, others have found that articular complaints are the commonest associated symptoms in patients with nephritis (5). Variability in these findings can be explained by the different ethnic background of the studied sample. We have studied associated symptoms in 71 patients with lupus nephritis and 142 SLE patients without renal involvement. This sample includes all lupus patients with nephritis followed in the last five years in our service, with biopsy proven disease except for those already admitted in class 6 . All included patients fulfilled at least 4 lupus classification criteria of the American College of Rheumatology. In this sample, 96.2\% (205/213) were females and $3.7 \%(8 / 213)$ males and the mean age was $38.3 \pm 11.8$ years.

The clinical profile showed $72.7 \%(155 / 213)$ of photosensitivity; $51.6 \%$ (110/213) of hemocytopenias; $50.2 \%$ (107/213) of arthritis; 49.7\% (106/213) of malar rash; $49.2(105 / 213)$ of alopecia; $48.3 \%$ $(103 / 213)$ of Raynaud; $45.5 \%$ (97/213) of mouth ulcers; $17.3 \%$ (37/213) of pleuritis; $14.4 \%$ (30/213) of discoid rash; $11.7 \%(25 / 213)$ of pericarditis; $6,5 \%(14 / 213)$ of subacute lupus skin lesions, $6.1 \%$ $(13 / 213)$ of cerebral vascular accidents, and 3,2\%

Table 1 - Clinical data in systemic lúpus patients with and without nephritis.

\begin{tabular}{|c|c|c|c|}
\hline Clinical finding & With nephritis $n=71$ & Without nephritis $n=142$ & $p$ \\
\hline Photosensitivity & $43-60.56 \%$ & $112-78.87 \%$ & $0.22\left(^{*}\right)$ \\
\hline Discoid rash & $6-8.45 \%$ & $24-16.90 \%$ & $0.09\left(^{*}\right)$ \\
\hline Sub acute skin lesions & $5-7.04 \%$ & $9-6.33 \%$ & $\left.1.0^{*}\right)$ \\
\hline Raynaud & $30-42.25 \%$ & $73-51.40 \%$ & $0.207\left(^{*}\right)$ \\
\hline Malar rash & $33-46.47 \%$ & $73-51.40 \%$ & $0.2(*)$ \\
\hline Alopecia & $45-63.38 \%$ & $60-42.25 \%$ & $0.03\left(^{*}\right)$ \\
\hline Mouth ulcers & $35-49.29 \%$ & $62-43.66 \%$ & $0.43\left(^{*}\right)$ \\
\hline Arthritis & $35-49.29 \%$ & $72-50.70 \%$ & $1.0\left(^{*}\right)$ \\
\hline Hemocytopenias & $35-49.29 \%$ & $75-52.81 \%$ & $1.0\left(^{*}\right)$ \\
\hline Secondary Sjögren & $8-11.26 \%$ & $20-14.08 \%$ & $0.56\left(^{*}\right)$ \\
\hline Cerebral vascular accident & $3-4.22 \%$ & $10-7.04 \%$ & $0.65(* *)$ \\
\hline Psychosis & $5-7.04 \%$ & $2-1.40 \%$ & $0.04(* *)$ \\
\hline Pleuritis & $17-23.94 \%$ & $20-14.08 \%$ & $0.07(*)$ \\
\hline Pericarditis & $14-19.71 \%$ & $11-7.74 \%$ & $0.01(*)$ \\
\hline Hypothyroidism & $11-15.49 \%$ & $21-14.78 \%$ & $0.32(*)$ \\
\hline
\end{tabular}


(7/213) of psychosis. In 15,02\% (32/213) there was associated hypothyroidism and in $13.1 \%$ (28/213), secondary Sjögren syndrome.

In the nephritis group we had $9.8 \%(7 / 71)$ with class $2 ; 12.6 \%$ (9/71) with class $3 ; 46.4 \%$ (33/71) of class $4 ; 16.9 \%$ (12/71) class 5 and $14.08 \%$ (10/71) of class 6. Comparing the clinical profile between patients with and without nephritis, we found data at table 1. In the studied population psychosis, pericarditis and alopecia were more common in nephritis patients than in those without it. Lupus patients having these symptoms should be carefully followed for nephritis development.

Skare T.L., Schönrock A.C. Rheumatology Unit Hospital Universitário Evangélico de Curitiba- PR - Brazil

\section{REFERENCES}

1. Dooley NA. Clinical and laboratory features of lupus nephritis. In Wallace DJ, Hahn BH (Eds): Dubois' Lupus Erythematosus, Philadelphia, Lippincott Williams \& Wilkins, 2007; 1112: 30.

2. Pistiner M, Wallace DJ, Nessin S, et al. Lupus erythematosus in the 1980s: a survey of 570 patients. Sem Arthritis Rheum 1991; 21: 55-64.

3. Le Thi Huong D., Papo T, Beaufils H, et al. Renal involvment in systemic lupus erythematosus: a study of 108 patients from a single center. Medicine 1999; 78: 148-66.

4. Helin H, Korpela M, Mustonen J, et al. Rheumatoid factor in rheumatoid arthritis associated renal disease in lupus nephritis. Ann Rheum Dis 1986; 45: 508-11.

5. Walker RJ, Bailey RR, Swainson CP, et al. Lupus nephritis: a 13 year experience. N Z Med J 1986: 99: 894-6. 